\title{
A Novel Type of Wireless V2H System with a Bidirectional Single-Ended Inverter Drive Resonant IPT
}

\author{
Hideki Omori $^{1 *}$, Shinya Ohara ${ }^{1}$, Masahito Tsuno ${ }^{2}$, Noriyuki Kimura ${ }^{1}$, Toshimitsu Morizane ${ }^{1}$ and Mutuo Nakaoka ${ }^{3}$ \\ ${ }^{1}$ Department of Electrical and Electronics Systems Engineering, Osaka Institute of Technology, Japan \\ ${ }^{2}$ Nichicon Co.Ltd., Kyoto Japan \\ ${ }^{3}$ University of Malaya, Kuala Lumpur, Malaysia
}

\begin{abstract}
Electric vehicles (EV) offer promise as an effective solution to environmental problems. One of the keys to their successful diffusion is the provision of adequate battery charging infrastructure. In order to create a charging infrastructure by installing equipment in such as locations as carports in private homes, the wireless battery charging system is very suitable. EVs can be used in smart house systems to supplement the energy storage. This vehicle to home $(\mathrm{V} 2 \mathrm{H})$ system essentially requires a bidirectional power transfer feature between the EV and home. This paper presents a new bidirectional inductive power transfer (IPT) system for wireless V2H with simplest components and low cost aiming at wide diffusion for home use. Proposed is a novel type of bidirectional wireless EV charging system with an efficient and compact type single-ended quasi-resonant high-frequency inverter for $\mathrm{V} 2 \mathrm{H}$.
\end{abstract}

Keywords: Wireless; Charger; Bidirectional; Single-ended inverter; Home use; Power transfer; EV

\section{Introduction}

In recent years, Electric Vehicles (EV) which are highly efficient as well as do not create air pollution, and offer promise as an effective solution to environmental problems with great advances of power electronic technology.

One of the key issues to their successful and wide diffusion is the provision of adequate battery charging infrastructure. In order to create a battery charging infrastructure by installing equipment in such as locations as carports in private homes, the inductive power transfer (IPT)-wireless battery charging system is indispensable for spread. The wireless battery charging system eliminates the use of power cables with plug. Merely by parking the car in a designated spot, the battery can be charged. It is a promising system for wider diffusion because it is easy and safe to use for a broad range of users including the elderly.

Usually as wireless EV charging power supply topologies have been half-bridge, push-pull, full bridge, boost half-bridge and boost fullbridge circuit configuration which have a plurality of power switching devices [1-4].

The authors have previously put into practice the cost-effective and high-efficiency single-ended quasi-resonant soft-switching inverter [5]. Although EVs are primarily consider as a method of clean transport, they can also be used in smart house systems to supplement the energy storage. This vehicle to home (V2H) system essentially requires a bidirectional power transfer feature between the EV and home.

This paper presents a new system with the simplest components and low cost aiming at wide diffusion for home use. From a practical point of view, simple high-frequency inverter circuit topologies have to be effectively selected in accordance with specific cost effective applications. Proposed is a novel type of wireless EV charging system based on IPT technology with an efficient and compact type singleended quasi-resonant high-frequency inverter. The single-ended inverter, which can operate in the frequency range from $20-30 \mathrm{kHz}$ under a self-excited ZVS control and its zero voltage crossing detector of resonant capacitor voltage is evaluated from an experimental point of view. Furthermore transfer power and efficiency have been successfully improved by pick-up circuit with resonant component. The output power of a proposed system is successfully improved by a resonant IPT circuit. EVs can be used in smart house systems to supplement the energy storage. This vehicle to home $(\mathrm{V} 2 \mathrm{H})$ system essentially requires a bidirectional power transfer feature between the EV and home. This paper presents a new bidirectional inductive power transfer (IPT) system for wireless V2H with simplest components and low cost aiming at wide diffusion for home use also. Proposed is a novel type of bidirectional wireless EV charging system with an efficient and compact type single-ended quasi- resonant high-frequency inverter for $\mathrm{V} 2 \mathrm{H}$. And a result of feasibility study by simulation and experiment is indicated for $\mathrm{V} 2 \mathrm{H} \mathrm{[6].}$

\section{Single-Ended EV Charging System Descriptions}

\section{System configuration}

An IPT-based wireless EV charging system is schematically illustrated in Figure 1. Figure 2 shows a proposed total system with a single-ended quasi-resonant high-frequency inverter. The system is mainly composed of a single-phase diode $\mathrm{D}_{1}$ rectifier with a $\mathrm{L}_{3}-\mathrm{C}_{3}$ filter, a single-ended quasi-resonant high-frequency inverter operating with a ZVS-PFM power regulation scheme in the frequency range of $20-30 \mathrm{kHz}$, resonant capacitor $\mathrm{C}_{1}$ with the primary coil $\mathrm{L}_{1}$ which is loosely coupled to the pickup coil $\mathrm{L}_{2}$ as load side, a single-phase diode $\mathrm{D}_{2}$ rectifier with a $\mathrm{L}_{4}-\mathrm{C}_{4}$ filter connected with the battery bank of $\mathrm{EV}$, and a specific power regulation control circuit due to the self-excited timing signal processing.

\section{Operating principle of a proposed wireless EV charger}

The periodic steady-state voltage and current operating waveforms of the single-ended quasi-resonant high-frequency inverter- fed DC-

${ }^{*}$ Corresponding author: Hideki Omori, Department of Electrical and Electronics Systems Engineering, Osaka Institute of Technology, Japan, Tel: +81-6-4300-6849; E-mail: hideki.omori@oit.ac.jp

Received September 12, 2016; Accepted September 19, 2016; Published September 26, 2016

Citation: Omori H, Ohara S, Tsuno M, Kimura N, Morizane T, et al. (2016) A Nove Type of Wireless V2H System with a Bidirectional Single-Ended Inverter Drive Resonant IPT. J Electr Electron Syst 5: 200. doi: 10.4172/2332-0796.1000200

Copyright: $\odot 2016$ Omori $\mathrm{H}$, et al. This is an open-access article distributed under the terms of the Creative Commons Attribution License, which permits unrestricted use, distribution, and reproduction in any medium, provided the original author and source are credited. 


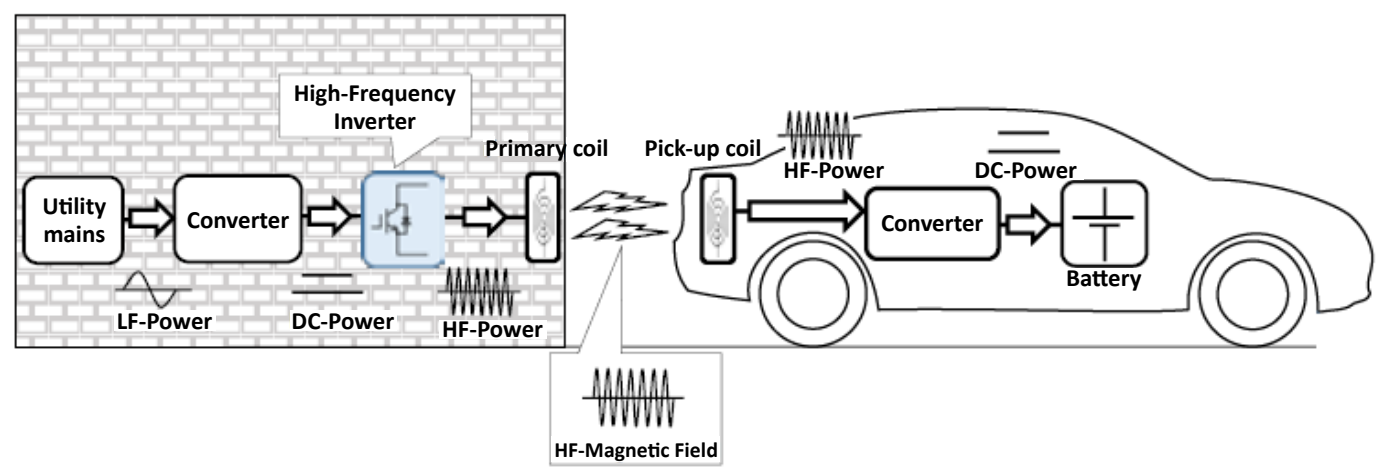

Figure 1: A schematic system configuration of wireless EV battery charger.

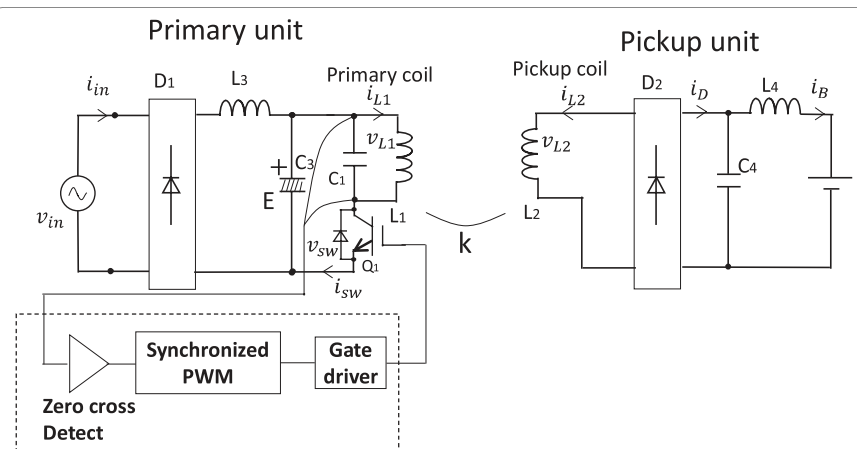

Figure 2: A proposed minimum component wireless battery charger using single-ended quasi-resonant high frequency inverter.

DC converter in Figure 2 are illustrated in Figure 3, which include Mode I, II, III, IV, during one switching cycle.

Figure 4 illustrates switching-mode equivalent circuits in accordance with on-off operating mode due to the single active switch $\mathrm{Q}_{1}$ and passive switches in secondary-side diode bridge $\mathrm{D}_{2}$. The circuit state in which the active switch $Q_{1}$ in the primary- side is cut off and passive switch $\mathrm{D}_{2}$ in the secondary-side is conducting is defined as Mode I and II (Figure 4a and $4 \mathrm{~b}$ ).

In Mode I (Figure 4a), when the active switch $\mathrm{Q}_{1}$ is turned off at $\mathrm{t}_{0}$, LC resonant tank circuit can operate. The inductor current and capacitor voltage become resonant state. Because of resonant operation, the voltage across the switch $Q_{1}$ begins to increase sinusoidally from zero voltage. The active switch $\mathrm{Q}_{1}$ is turned off with ZVS (Zero Volt Switching) transition. The inductor current $\mathrm{iL}_{1}, \mathrm{iL}_{2}$ through the primary coil $\mathrm{L}_{1}$, the secondary coil $\mathrm{L}_{2}$ are decreasing. As soon as the inductor current $\mathrm{iL}_{2}$ reaches zero at $\mathrm{t}_{1}$, the state of $\mathrm{D}_{2}$ moves to Mode II shown in Figure $4 \mathrm{~b}$, the inductor voltage $\mathrm{v}_{\mathrm{L} 2}$ across the secondary coil $\mathrm{L}_{2}$ becomes $-\mathrm{V}_{\mathrm{C} 4}$ from $\mathrm{V}_{\mathrm{C} 4}$.

As soon as the resonant capacitor voltage reaches the supply DC voltage $\mathrm{V}_{\mathrm{C}_{3}}$ at $\mathrm{t}_{2}$, the voltage across $\mathrm{Q}_{1}$ becomes zero. At this point, the antiparallel diode of $\mathrm{Q}_{1}$ turns on naturally. The operating mode becomes Mode III shown in Figure 4c. The circuit state in which the active switch $\mathrm{Q}_{1}$ in the primary-side and passive switch $\mathrm{D}_{2}$ in the secondary-side are both conducting is defined as Mode III, IV (Figure $4 \mathrm{c}$ and $4 \mathrm{~d}$ ). The inductor current $\mathrm{iL}_{1}$ through the primary coil $\mathrm{L}_{1}$ and the active switch current $\mathrm{iQ}_{1}$ increase in a function time as illustrated in Mode III, IV of Figure 3 during Ton period.

When the secondly current $\mathrm{iL}_{2}$ reaches to zero at $\mathrm{t}_{3}$, the state of

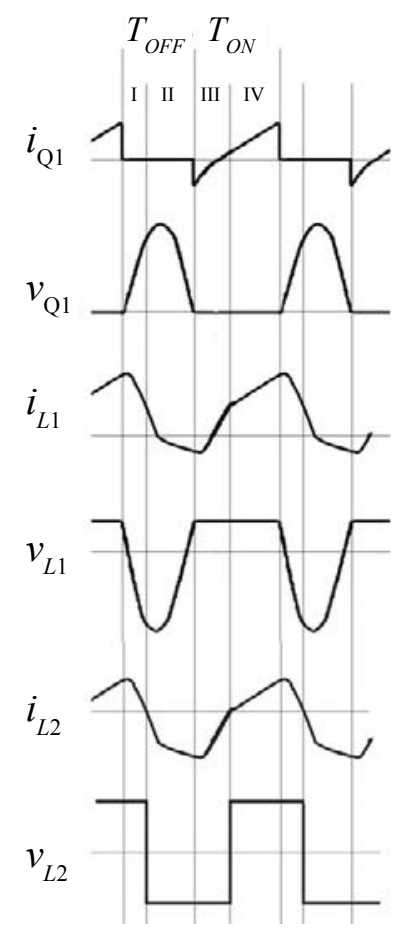

Figure 3: Relevant voltage and current waveforms of quasi-resonant highfrequency inverter and high-frequency rectifier sides.

$\mathrm{D}_{2}$ moves to Mode IV shown in Figure $4 \mathrm{~d}$, and the secondary voltage $\mathrm{V}_{\mathrm{L} 2}$ changes to $\mathrm{V}_{\mathrm{C} 4}$ from $-\mathrm{V}_{\mathrm{C} 4}$. The active switch $\mathrm{Q}_{1}$ is turned off in accordance with its gate pulse duration time Ton

Judging from the operating voltage $\mathrm{v}_{\mathrm{Q} 1}$ and current $\mathrm{i}_{\mathrm{Q} 1}$ of the active switch, it is understood that the switch $\mathrm{Q}_{1}$ can achieve a soft -switching turn-on transition with ZVS. Note that the diode $\mathrm{D}_{2}$ in the secondary side can operate under a principle of ZCS (Zero Current Switching). As a result, the recovery current of $\mathrm{D}_{2}$ is considerably small, and switching power loss of $\mathrm{D}_{2}$ as well as switching noise can be minimized effectively. The active switch $Q_{1}$ can achieve the complete soft switching transitions with ZVS at turn-on and turn-off. The synchronized PWM oscillator generates pulses synchronized with $\mathrm{v}_{\mathrm{L} 1}$ to achieve ZVS turn-on.

This system can supply an approximately constant current to battery owing to leakage inductance of wireless coupling planar coils without sensing any signals from the secondary-side pick-up coil circuit in EV. 


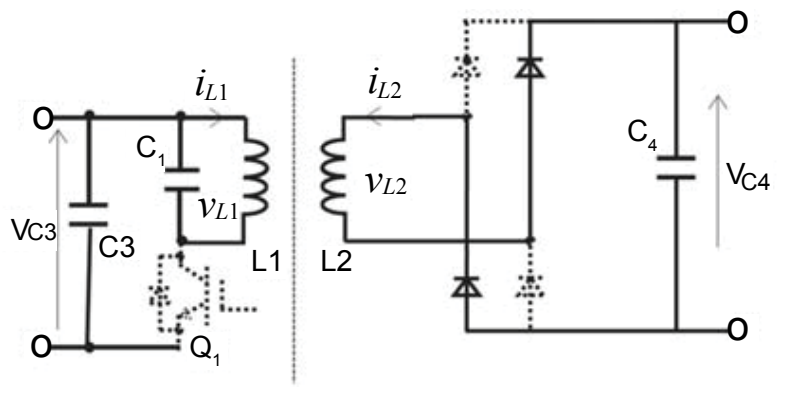

(a) Mode I
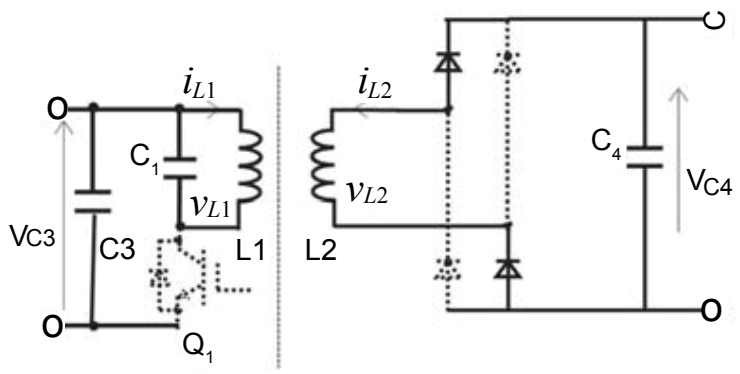

(b) Mode II
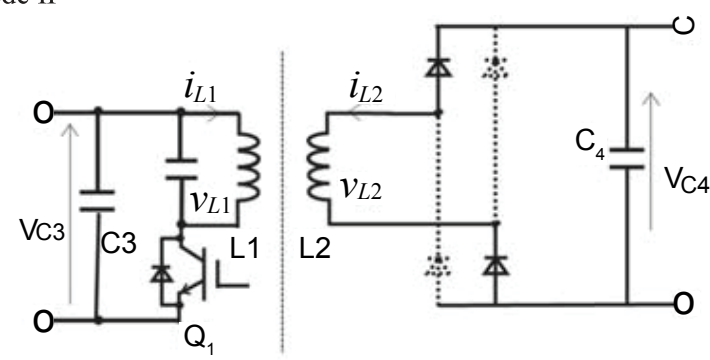

(c) Mode III

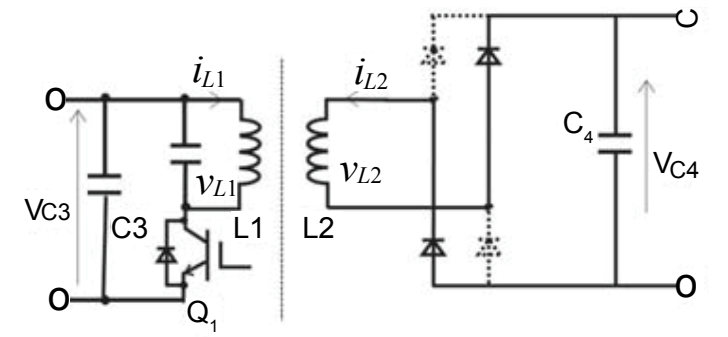

(d) Mode IV

Figure 4: Equivalent circuits for switch-mode states of single-ended highfrequency inverter under battery charging scheme.

Transfer-power improvement by a resonant pick-up Circuit equations of two planar spiral coils are given by

$$
\left.\begin{array}{l}
v_{L 1}=r_{1} i_{1}+L_{1} \frac{d i_{L 1}}{d t}+M \frac{d i_{L 2}}{d t} \\
v_{L 2}=r_{2} i_{2}+M \frac{d i_{L 1}}{d t}+L_{2} \frac{d i_{L 2}}{d t}
\end{array}\right\}
$$

Where,

$\mathrm{L}_{1}, \mathrm{~L}_{2}$ : self-inductance of the primary-side power feeding coil and secondary side power receiving coil. $\mathrm{r}_{1}, \mathrm{r}_{2}$ : internal resistances of each planar coil.

K: electromagnetic coupling coefficient of two planar spiral coils.

$\mathrm{M}$ : mutual inductance between $\mathrm{L}_{1}$ and $\mathrm{L}_{2}$, which is influenced upon gap distance variable.

$$
M=k \sqrt{L_{1} L_{2}}
$$

Output power of the system shown in Figure 2 is approximately represented by the following Equation:

$$
P_{n r}=\frac{\left|V_{L 2}\right|^{2}}{R_{0}}=\frac{k^{2}}{R_{0}+\omega^{2} L_{2}^{2}\left(1-k^{2}\right)^{2} \frac{1}{R_{0}}} \frac{L_{2}}{L_{1}} V_{L 1}^{2}
$$

Where,

$\mathrm{V}_{\mathrm{L} 1}, \mathrm{~V}_{\mathrm{L} 2}$ : effective voltages of the power feeding coil and the power receiving coil.

$\mathrm{R}_{0}$ : equivalent resistance of the output circuit.

$\omega$ : operating frequency of the inverter.

On the other hand, output power $\mathrm{P}_{\mathrm{r}}$ in the case of a power receiving coil $\mathrm{L}_{2}$ with a parallel connected resonant capacitor $\mathrm{C}_{2}$ is approximately represented as following equation:

$$
P_{n r}=\frac{\left|V_{L 2}\right|^{2}}{R_{0}}=\frac{k^{2}}{R_{0}\left\{1-\omega^{2} L_{2} C_{2}\left(1-k^{2}\right)\right\}^{2}+\omega^{2} L_{2}{ }^{2} \frac{\left(1-k^{2}\right)^{2}}{R_{0}}} \frac{L_{2}}{L_{1}} V_{L 1}{ }^{2}
$$

$\mathrm{P}_{\mathrm{r}}$ can be compared to $\mathrm{P}_{\mathrm{nr}}$ as follows:

$$
\begin{gathered}
\frac{P_{n r}}{P_{r}}=\frac{R_{0}\left\{1-\left(\frac{\omega}{\omega_{0}}\right)^{2}\left(1-k^{2}\right)\right\}^{2}+\omega^{2} L_{2}{ }^{2} \frac{\left(1-k^{2}\right)^{2}}{R_{0}}}{R_{0}+\omega^{2} L_{2}{ }^{2} \frac{\left(1-k^{2}\right)^{2}}{R_{0}}} \\
=1-\frac{R_{0}\left(\frac{\omega}{\omega_{0}}\right)^{2}\left(1-k^{2}\right)\left\{2-\left(\frac{\omega}{\omega_{0}}\right)^{2}\left(1-k^{2}\right)\right\}}{R_{0}+\omega^{2} L_{2}{ }^{2} \frac{\left(1-k^{2}\right)^{2}}{R_{0}}}
\end{gathered}
$$

With $\omega_{0}=\frac{1}{\sqrt{L_{2} C_{2}}}$

The resonant transfer power $\mathrm{P}_{\mathrm{r}}$ is higher than the non-resonant transfer power $\mathrm{P}_{\mathrm{nr}}$ under the condition of, then proposed is a resonant wireless EV charger with the pick-up side resonant capacitor in Figure 2 system [7].

\section{Experimental Results}

\section{Wireless coupling coil units}

It is noted that the primary- side power feeding unit $\mathrm{L}_{1}$ is loosely coupled to the pick-up coil $\mathrm{L}_{2}$ of the secondary side power receiving unit for the battery charging power supply. In actual, these circular coils in the primary and secondary-side are assembled by the power litz wires in order to reduce power losses due to the skin effect. Two contactless planar and circular coil units with ferrite core sheets; power sending coil and power receiving coil are depicted in Figure 5.

We propose a power transfer configuration through a rear glass, because it is easy to install the pick-up unit. Then the diameter of coils is 


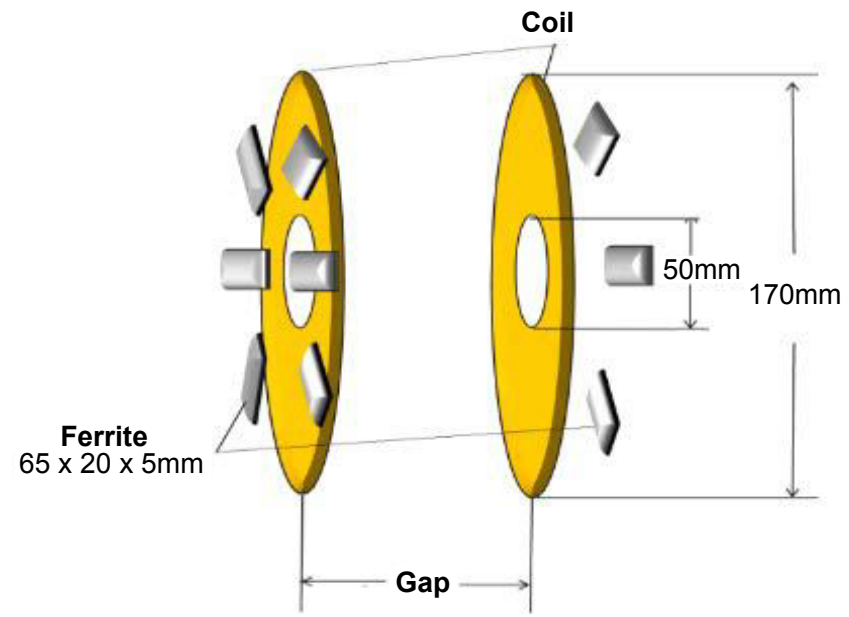

Figure 5: A wireless electro-magnetic structure with two planar and circular type coil units. (Winding 22 turns, Diameter $\Phi 170 \mathrm{~mm}$, Thickness $2 \mathrm{~mm}$, Inductance $60 \mu \mathrm{H}$, Resistance $20 \mathrm{~m} \Omega$, Gap distance typ. $30 \mathrm{~mm}$ ).

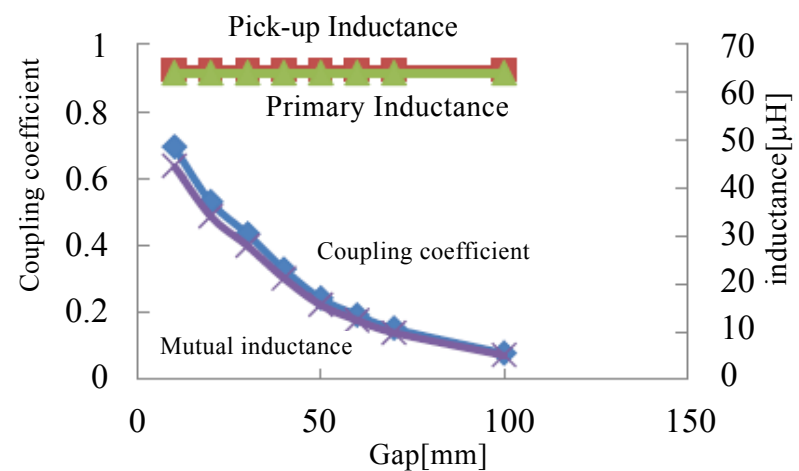

Figure 6: Relationship of circuit parameters of two planar coils for the gap distance variable.

$170 \mathrm{~mm}$, and the typical gap distance is $30 \mathrm{~mm}$ which include thickness of the rear glass and clearance.

As a matter of fact, some circuit parameters; mutual inductance $\mathrm{M}$ and magnetic coupling coefficient $\mathrm{k}$ of two planar spiral coils can depend upon the gap distance variable. Primary inductance $\mathrm{L}_{1}$ and secondary inductance $\mathrm{L}_{2}$ is not depending on gap (Figure 6).

\section{Operating characteristics}

The measured waveforms in a proposed EV charging system are shown in Figure 7. The active switch $\mathrm{Q}_{1}$ turn-on and turn-off by ZVS, and the self-excited ZVS control scheme well functions. In particular, in single-ended quasi-resonant inverter, note that the maximum voltage applied to the active switch $\mathrm{Q}_{1}$ becomes relatively high because of quasiresonant operation of primary side.

The measured value of output power in non-resonant case and resonant case vs. load characteristics for gap distance from 30 to $50 \mathrm{~mm}$ is shown in Figure 8. The output power with resonant pickup circuit is 1.5-2 times higher than that with non-resonant one. Measured power transfer efficiency is $90 \%$ under $30 \mathrm{~mm}$ gap in the resonant pick-up case.

A prototype of EV equipped with pick-up coil unit of the resonant IPT-wireless charging system and power feeding coil unit is shown in
Figure 9a. The wireless charging system can charge $4.5 \mathrm{kWh}$ in 5 hours as a feasibility study result as shown in Figure $9 \mathrm{~b}$.

\section{A Wireless V2H System With Bidirectional Resonant Single-Ended Inverter}

A smart house with a vehicle to home (V2H) system is shown in Figure 10. Connected EV plays a role to supplement a storage battery system. As it is easy to connect EV the house by a wireless vehicle to home system, the EV is efficiently used for the smart house. The vehicle to home $(\mathrm{V} 2 \mathrm{H})$ system essentially requires a bidirectional power transfer feature between the EV and home. A new system configuration by a single-ended inverter with a resonant IPT circuit for bidirectional power transfer is shown in Figure 11. The proposed system is with simplest components and low cost.

In the EV charging mode, a home-side single-ended inverter produces high frequency power which is transferred to vehicle side circuit by resonant IPT as shown in Figure 12 left side. Capacitance $\mathrm{C}_{1}$ in home-side circuit operates as resonant capacitance for ZVS transition and capacitance $\mathrm{C}_{2}$ in vehicle-side circuit operates as resonant capacitance for resonant IPT. Input current $\mathrm{I}_{\mathrm{L} 3}$ smoothed by DC choke $\mathrm{L}_{3}$ is constant without ripple. Also output current $\mathrm{I}_{\mathrm{L} 4}$ smoothed by DC choke $\mathrm{L}_{4}$ is constant without ripple (Figure 12).

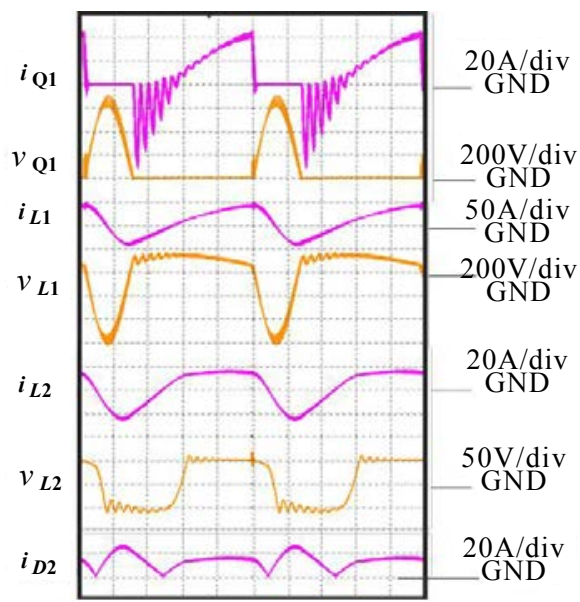

Figure 7: Measured voltage and current waveforms of quasi-resonant highfrequency inverter. (10 $\mu \mathrm{s} / \mathrm{div})$.

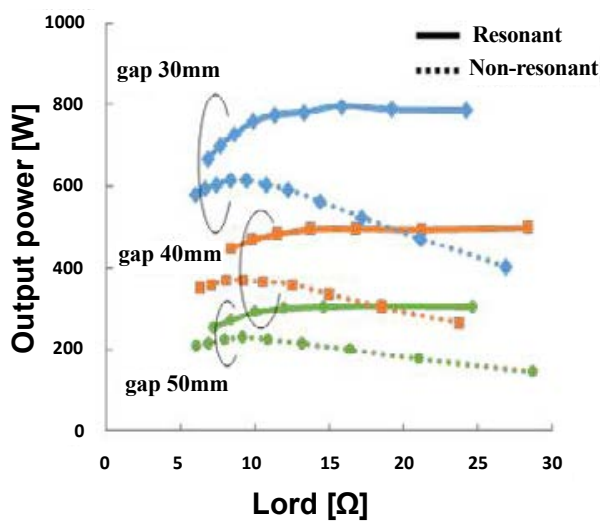

Figure 8: Observed output power vs. lord characteristics. (Diameter $170 \mathrm{~mm}$, $\mathrm{C} 10.3 \mu \mathrm{F}, \mathrm{C} 20.3 \mu \mathrm{F}, \mathrm{C} 32200 \mu \mathrm{F}, \mathrm{C} 46 \mu \mathrm{F}, \mathrm{L} 160 \mu \mathrm{H}, \mathrm{L} 260 \mu \mathrm{H}, \mathrm{L} 390 \mu \mathrm{H}, \mathrm{L} 4$ $90 \mu \mathrm{H}$, VB $55 \mathrm{~V}$, Vac 100 V $60 \mathrm{~Hz}$ ) 
Citation: Omori H, Ohara S, Tsuno M, Kimura N, Morizane T, et al. (2016) A Novel Type of Wireless V2H System with a Bidirectional Single-Ended Inverter Drive Resonant IPT. J Electr Electron Syst 5: 200. doi: 10.4172/2332-0796.1000200

Page 5 of 8

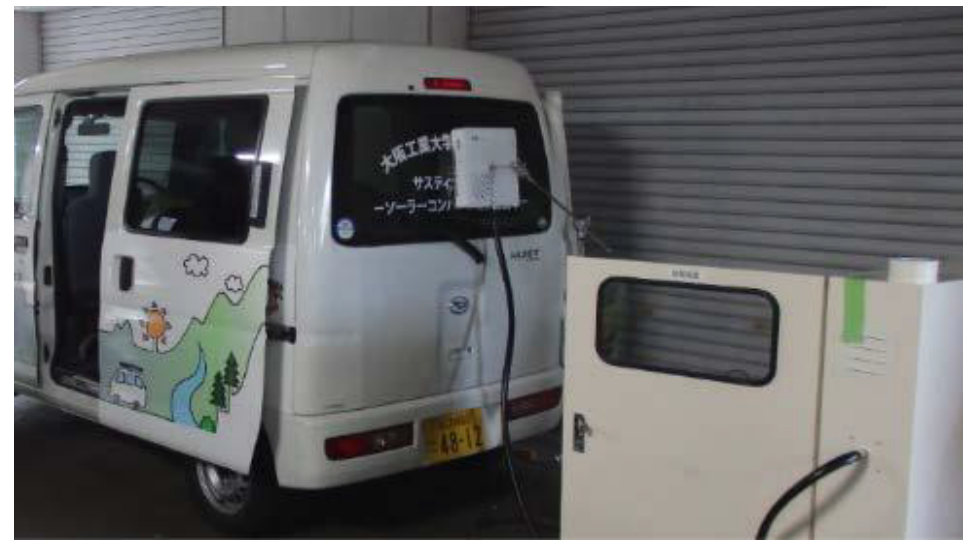

(a): A prototype of EV equipped with developed charging system. (Rear side power transfer)

Figure 9: A feasibility study result of the developed charging system.

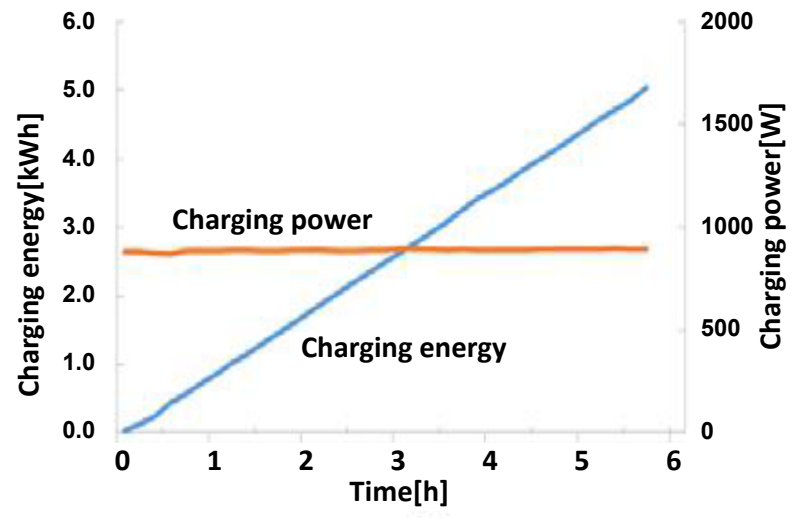

(b): Experimental result of EV charging

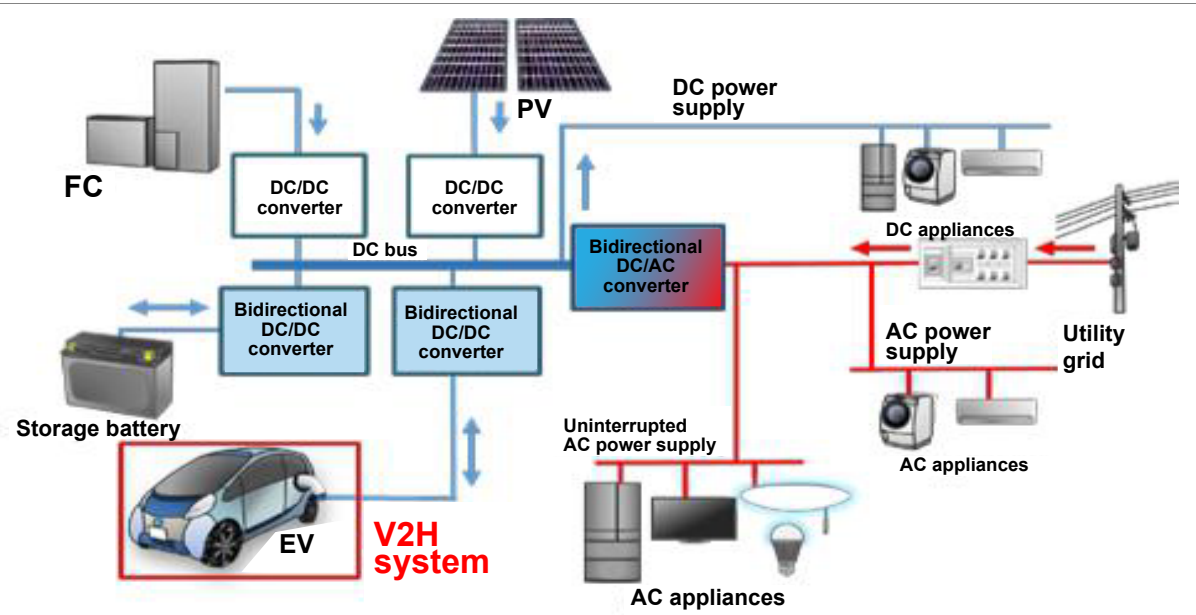

Figure 10: A smart house construction including wireless $\mathrm{V} 2 \mathrm{H}$.

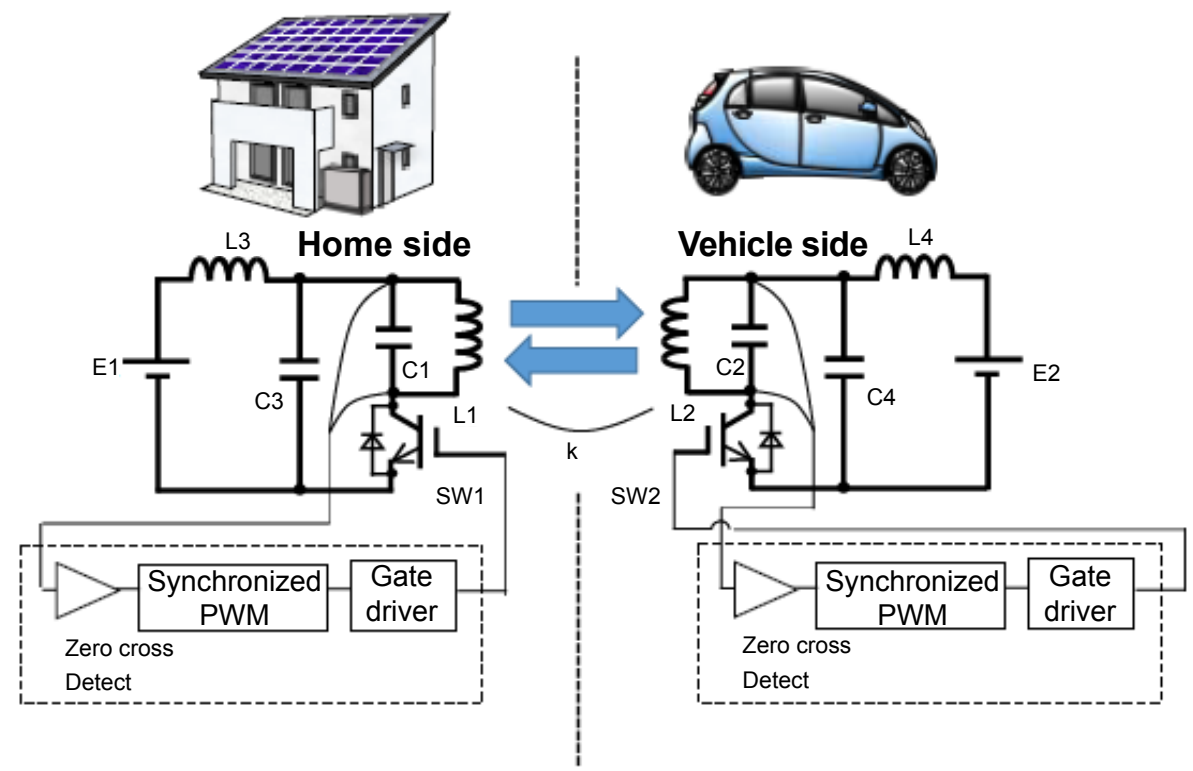

Figure 11: A new simplest component wireless $\mathrm{V} 2 \mathrm{H}$ system with bidirectional single-ended quasi-resonant high-frequency converters. 


\section{Home to Vehicle}

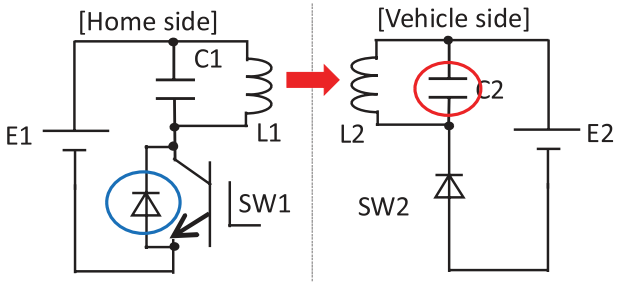

An antiparallel diode of switch operates as a rectifier for power receiving.

\section{Vehicle to Home}

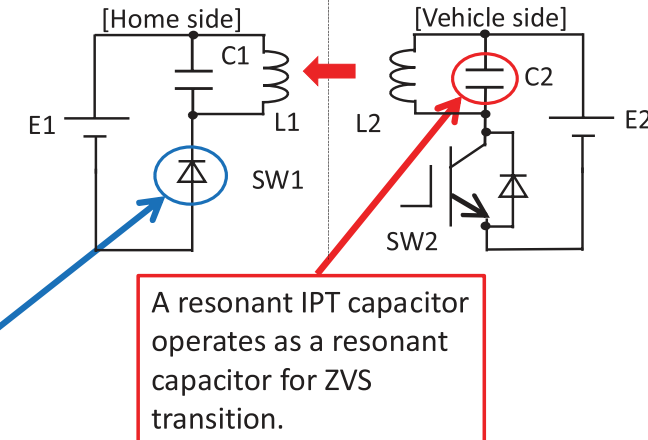

Figure 12: Operation principle of the proposed wireless $\mathrm{V} 2 \mathrm{H}$ system with bidirectional single-ended converters.

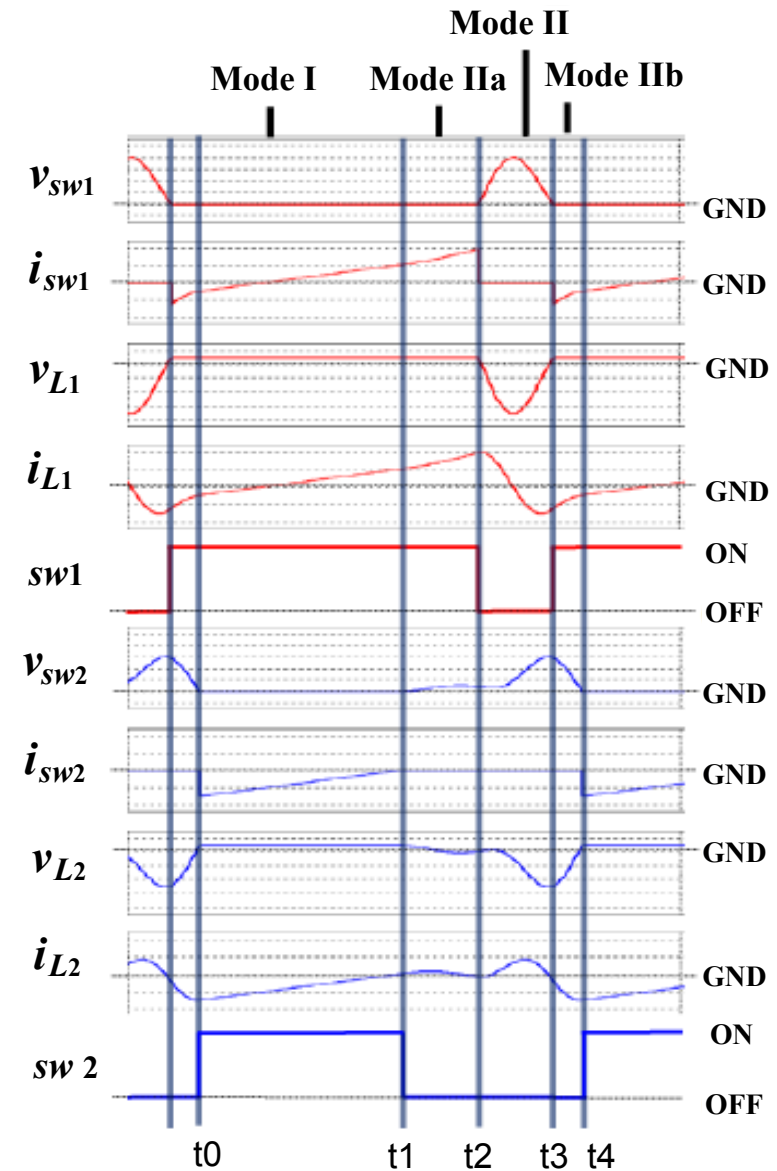

Figure 13: Simulated waveforms of the new bidirectional circuit using quasi-resonant high-frequency inverters (Home to Vehicle).

On the other hand, in the EV battery energy using mode, a vehicle-side single-ended inverter produces high frequency power which is transferred to home side circuit by resonant IPT indicated in Figure 12 right side. Capacitance $\mathrm{C}_{2}$ in vehicle-side circuit operates as resonant capacitance for ZVS transition and capacitance $\mathrm{C}_{1}$ in homeside circuit operates as resonant capacitance in power receiving for resonant IPT.

Figure 13 shows simulated operating waveforms of a proposed bidirectional circuit using a quasi-resonant high-frequency inverter in home to vehicle mode. The active switch SW1 is turned off and turned on with ZVS transition. And the active switch SW2 is kept off. A vehicle side circuit operates as a rectifier with a pick-up resonant circuit. This system operates as a resonant forward converter. Figure 14 shows operating modes of the bidirectional single-ended converter with resonant IPT in home to vehicle mode.

Figure 15 shows measured operating waveforms of proposed wireless $\mathrm{V} 2 \mathrm{H}$ system. These waveforms are same as above mentioned simulation waveforms. The ZVS control scheme works well. Measured 
Citation: Omori H, Ohara S, Tsuno M, Kimura N, Morizane T, et al. (2016) A Novel Type of Wireless V2H System with a Bidirectional Single-Ended Inverter Drive Resonant IPT. J Electr Electron Syst 5: 200. doi: 10.4172/2332-0796.1000200

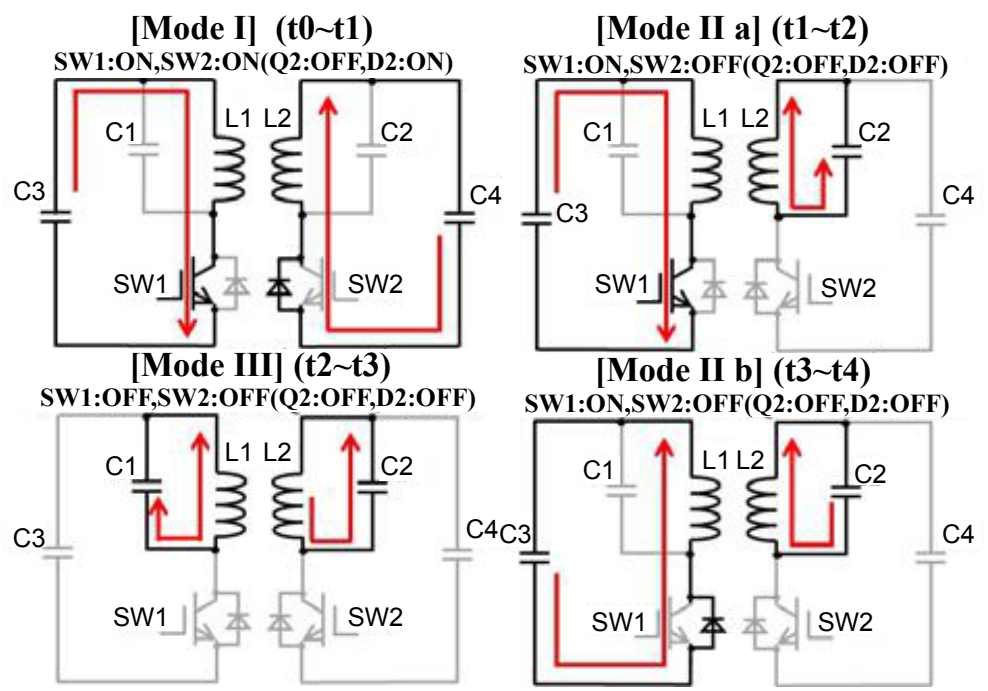

Figure 14: Operating modes of the new bidirectional circuit using quasi-resonant high-frequency inverters (Home to Vehicle)

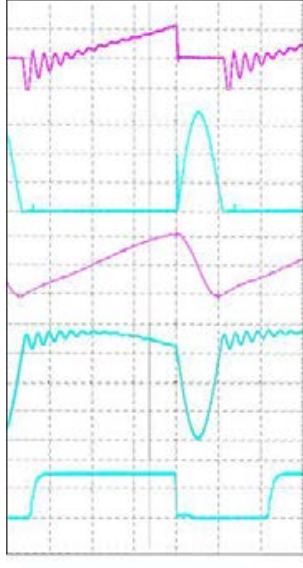

Time 10us/div Home side

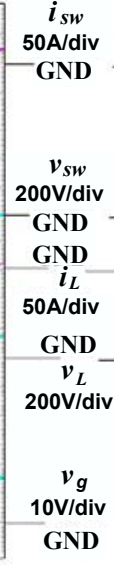

GND

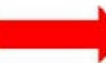

(a): Home to Vehicle

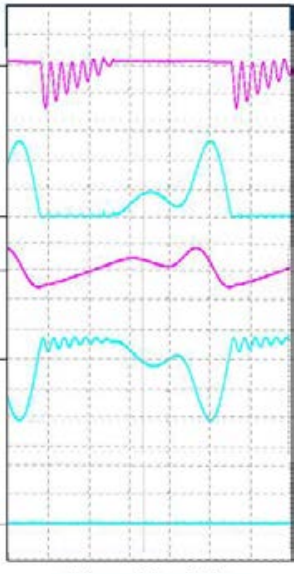

Time $10 \mu \mathrm{s} / \mathrm{div}$ Vehicle side

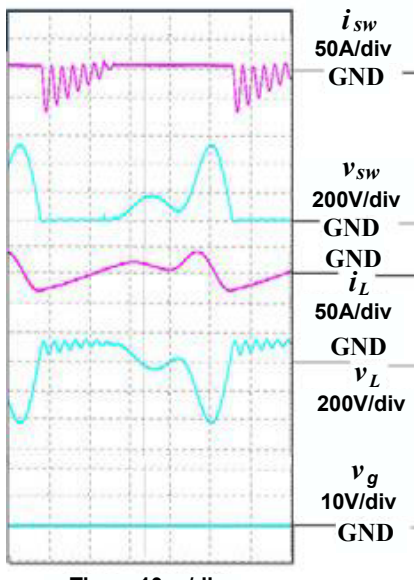

Home side

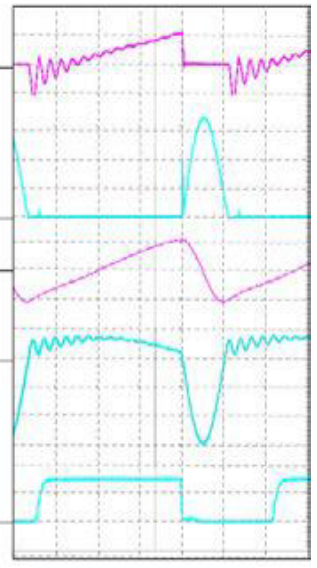

Time 10us/div Vehicle side

Figure 15: Measured waveforms of the bidirectional circuit using quasi-resonant high-frequency converters.

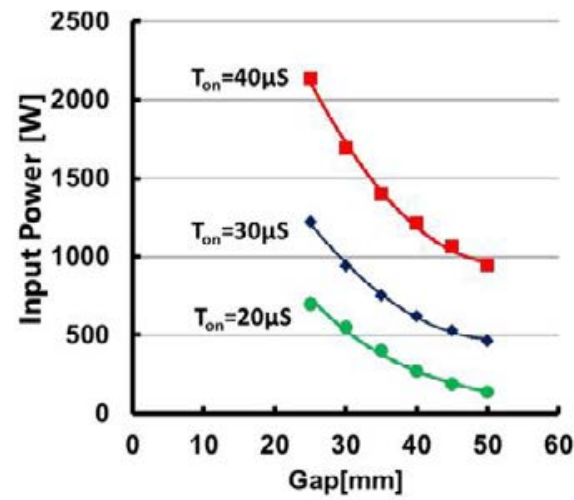

(a): Home to Vehicle

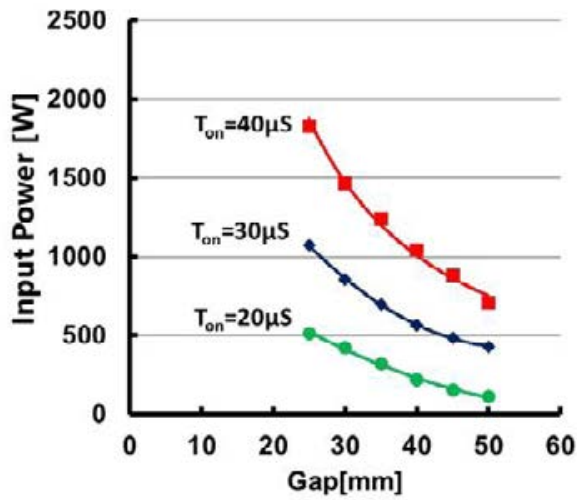

(b): Vehicle to Home

Figure 16: Observed output power vs. gap distances of the bidirectional circuit using quasi-resonant high-frequency inverters. (Diameter $170 \mathrm{~mm}$, C1 $0.3 \mu \mathrm{F}, \mathrm{C} 2$ $0.3 \mu \mathrm{F}, \mathrm{C} 36 \mu \mathrm{F}, \mathrm{C} 46 \mu \mathrm{F}, \mathrm{L} 135 \mu \mathrm{H}, \mathrm{L} 235 \mu \mathrm{H}, \mathrm{L} 390 \mu \mathrm{H}, \mathrm{L} 490 \mu \mathrm{H}, \mathrm{E} 1100 \mathrm{~V}, \mathrm{E} 2100 \mathrm{~V})$. 
Citation: Omori H, Ohara S, Tsuno M, Kimura N, Morizane T, et al. (2016) A Novel Type of Wireless V2H System with a Bidirectional Single-Ended Inverter Drive Resonant IPT. J Electr Electron Syst 5: 200. doi: 10.4172/2332-0796. 1000200

waveforms of vehicle to home mode also show the reverse operation scheme well function.

Figure 16a shows output power characteristics of home to vehicle mode. The output power decreases depending on gap distance, and can be controlled by conduction time TON. Figure 16b shows the output power characteristics in home to vehicle power transfer mode which same as those in vehicle to home mode.

\section{Conclusion}

Presented has been a new wireless EV charging system based on IPT technology with minimum components and low cost aiming at wide diffusion for home use. From a practical point of view, an efficient and compact type single-ended quasi-resonant high-frequency inverter was selected. The single-ended inverter which can operate in the frequency range from $20-30 \mathrm{kHz}$ under a synchronized self-excited ZVS control and its zero voltage crossing detector of resonant capacitor voltage is evaluated from an experimental point of view. Output power of a proposed system has been successfully improved by a resonant IPT circuit. The output power with resonant pick-up circuit was 1.5-2 times higher than that with non-resonant one. Furthermore proposed has been a new resonant IPT wireless V2H system with a simplest and low cost bidirectional single-ended converter aiming at wide diffusion for home use also. And a result of feasibility study for V2H by simulation and experiment was indicated.

\section{References}

1. Thrimawithana DJ, Madawala UK, Shi Y (2010) Design of a Bi-Directional Inverter for a Wireless V2G System. Proc. IEEE International Conf. on Sustainable Energy Technologies, ICSET, Kandy, Sri Lanka.

2. Huh J, Lee W, Cho GH, Lee B, Rim CT (2011) Characterization of Nove Inductive Power Transfer Systems for On-Line Electric Vehicles. Proc Annual IEEE Applied Power Electronics Conference and Exposition, APEC, Texas, USA.

3. Machino S, Kozako M, Harada K, Hikita M, Hotta K, et al. (2011) Construction and Characteristics of Wireless Resonance Type Inductive Power Supply. Proc Japan Industry Applications Society Conf Okinawa, Japan, CD-ROM 2-13.

4. Kai T, Kraisorn T, Minagawa Y (2011) A Study on Receiver Circuit Topology of Non-contact Charger for Electric Vehicle. Proc Japan Industry Applications Society Conf. Okinawa, Japan, CD-ROM 2-16.

5. Omori H, Nakaoka M (1997) Generic Circuit Topologies and Their Performance Evaluations of Single-Ended Resonant High-Frequency Inverters for InductionHeated Cooking Appliances. Trans on IEE Japan 117: 150-159.

6. Omori H, Iga Y, Morizane T, Kimura N, Nakagawa K, et al. (2012) A Nove Wireless EV Charger using SiC Single-Ended Quasi-Resonant Inverter for Home Use. International Power Electronics and Motion Control Conference and Exposition, Novisad, Serbia.

7. Omori H, Iga $\mathrm{Y}$, Fukuoka H, Morizane T, Kimura N, et al. (2013) A New Bidirectional Resonant IPT EV Charging System with Single-Ended Inverter Electrical Drives and Power Electronics, Dublovnik, CROATIA. 